\title{
Predictors of Outcomes after Correction of Acute Type A Aortic Dissection under Moderate Hypothermic Circulatory Arrest and Antegrade Cerebral Perfusion
}

\author{
George Samanidis ${ }^{1}$, MD; Charalampos Katselis ${ }^{1}$, MD; Constantinos Contrafouris ${ }^{1}$, MD, PhD; Georgios Georgiopoulos², \\ MD; loannis Kriaras ${ }^{3}$, MD; Theofani Antoniou ${ }^{4}$, MD, PhD; Konstantinos Perreas' ${ }^{1}$, FRCS, PhD
}

DOI: 10.21470/1678-9741-2017-0123

\section{Abstract}

Introduction: Hypothermic circulatory arrest is widely used for correction of acute type A aortic dissection pathology. We present our experience of $\mathbf{4 5}$ consecutive patients operated in our unit with bilateral antegrade cerebral perfusion and moderate hypothermic circulatory arrest.

Methods: Between January 2011 and April 2015, 45 consecutive patients were admitted for acute type $A$ aortic dissection and operated emergently under moderate hypothermic circulatory arrest and bilateral antegrade cerebral perfusion.

Results: Mean age was $58 \pm 11.4$ years old. Median circulatory arrest time was 41.5 (30-54) minutes while the 30-day mortality and postoperative permanent neurological deficits rates were $6.7 \%$ and $13.3 \%$, respectively. Unadjusted analysis revealed that the factors associated with 30-day mortality were: preoperative hemodynamic instability (OR: $14.8,95 \% \mathrm{Cl}: 2.41,90.6, P=0.004)$; and postoperative requirement for open sternum management (OR: $5.0,95 \% \mathrm{Cl}: 1.041,24.02, P=0.044$ ) while preoperative hemodynamic instability (OR: $8.8,95 \% \mathrm{Cl}: 1.41,54.9, P=0.02)$ and postoperative sepsis or multiple organ dysfunction (OR: 13.6, $95 \%$ $\mathrm{Cl}: 2.1,89.9, P=0.007)$ were correlated with neurological dysfunction. By multivariable logistic regression analysis, postoperative sepsis and multiple organ dysfunction independently predicted (OR: 15.9, $95 \% \mathrm{Cl}: 1.05,96.4, P=0.045)$ the incidence of severe postoperative neurological complication. During median follow-up of 6 (2-12) months, the survival rate was $\mathbf{8 6 . 7 \%}$.

Conclusion: Bilateral antegrade cerebral perfusion and direct carotid perfusion for cardiopulmonary bypass, in the surgical treatment for correction of acute aortic dissection type $A$, is a valuable technique with low 30-day mortality rate. However, postoperative severe neurological dysfunctions remain an issue that warrants further research.

Keywords: Cerebrovascular Circulation. Hypothermia, Induced/Methods. Perfusion/Methods. Aneurysm, Dissecting/ Surgery. Aortic Aneurysm/Surgery.

Abbreviations, acronyms \& symbols

\begin{tabular}{|c|c|c|c|}
\hline AAD & $=$ Acute type $\mathrm{A}$ aortic dissection & HTK & = Histidine-tryptophan-ketoglutarate \\
\hline ACP & $=$ Antegrade cerebral perfusion & ICU & $=$ Intensive care unit \\
\hline AF & $=$ Atrial fibrillation & MHCA/BACP & = Moderate hypothermic circulatory arrest \\
\hline BACP & $=$ Bilateral antegrade cerebral perfusion & & and bilateral antegrade cerebral perfusion \\
\hline CA & $=$ Circulatory arrest & MHCA/UACP or BACP & $=$ Moderate hypothermic circulatory arrest \\
\hline CCA & $=$ Common carotid artery & & with unilateral or bilateral cerebral perfusion \\
\hline CNS & $=$ Central nervous system & PND & $=$ Permanent neurological dysfunctions \\
\hline CPB & $=$ Cardiopulmonary bypass & RCP & $=$ Retrograde cerebral perfusion \\
\hline CT & $=$ Computed tomography & TIA & $=$ Transient ischemic attack \\
\hline DHCA & $=$ Deep hypothermic circulatory arrest & TND & = Temporary neurological dysfunctions \\
\hline DHCA/UACP or BACP & $\begin{aligned}= & \text { Deep hypothermic circulatory arrest with } \\
& \text { unilateral or bilateral cerebral perfusion }\end{aligned}$ & UACP & $=$ Unilateral antegrade cerebral perfusion \\
\hline
\end{tabular}

'First Department of Adult Cardiac Surgery, Onassis Cardiac Surgery Center, Athens, Greece.

2First Department of Cardiology, Hippokration Hospital, University of Athens, Athens, Greece.

${ }^{3}$ Department of Cardiac Surgery Intensive Care Unit, Onassis Cardiac Surgery Center, Athens, Greece.

${ }^{4}$ Department of Anesthesiology, Onassis Cardiac Surgery Center, Athens, Greece.

This study was carried out Onasseio Kardioxeirourgiko Kedro - First Department of Adult Cardiac Surgery, Athens, Greece.
No conflict of interest

No financial support.

Correspondence Address:

George Samanidis

Onassis Cardiac Surgery Center

356 Syggrou Av., 17674 - Athens, Greece

E-mail: gsamanidis@yahoo.gr 


\section{INTRODUCTION}

Hypothermic circulatory arrest (CA) is widely used for correction of acute type A aortic dissection (AAD). In an attempt to establish a bloodless surgical field and ameliorate brain protection, which is more vulnerable in this case, a variety of techniques for cardiopulmonary bypass (CPB) and cerebral perfusion during CA have been suggested over the years ${ }^{[1-3]}$.

We present our experience of 45 consecutive patients who underwent $A A D$ correction with moderate hypothermic $C A$ and bilateral antegrade cerebral perfusion (MHCA/BACP) via the common carotid arteries.

\section{METHODS}

\section{Study Population}

Between January 2011 and April 2015, 45 consecutive patients underwent an emergency operation for type A AAD (with or without aortic root and valve involvement) with MHCA/BACP. The preoperative diagnosis was established with computed tomography (CT) of thoracic and abdominal aorta, including aortic arch branches. All preoperative, perioperative and postoperative data were recorded.

Two patients were operated with preoperative minor neurological dysfunction [transient ischemic attack (TIA)].

This study was carried out according to the principles outlined in the Declaration of Helsinki. It is a retrospective analysis approved by the hospital's institutional ethics committee (546/30-04-2015) and all patients gave their informed consent prior to the operation.

\section{Surgical Technique}

All patients underwent an emergency surgical correction of AAD within 24 hours of admission. The briefly applied surgical technique consisted of standard median sternotomy and CPB via: 1) right or left carotid artery (connecting through a 10-mm synthetic graft)/ bicaval cannulation in 42 patients and 2) femoral artery/bicaval cannulation in 3 patients. Gradual cooling of the body $\left(1^{\circ} \mathrm{C} / 5 \mathrm{~min}\right)$ and alpha-stat ( $\mathrm{pH}$ management) was utilized. Myocardial arrest and protection was achieved with retrograde delivery of histidinetryptophan-ketoglutarate (HTK) crystalloid solution (Custodiol ${ }^{\circledR}$ ).

Once CPB was instituted, the aortic cross-clamp was applied, the cooling initiated and, with the heart stopped, correction of the proximal ascending aorta \pm aortic root was undertaken, including any other required correction.

When bladder temperature reached $\approx 23^{\circ} \mathrm{C}$, the head was packed in ice and the circulation, except for the carotids, was interrupted. CPB and antegrade cerebral perfusion (ACP) were achieved using synthetic graft $(10 \mathrm{~mm})$ in the right or left common carotid artery (CCA) and selective cannulation of the contralateral CCA. Where CBP was established with femoral artery/bicaval cannulation. ACP was performed with selective cannulation of both CCA. The ACP blood flow was $10 \mathrm{~mL} / \mathrm{kg} / \mathrm{min}$ (perfusion pressure around $50-70 \mathrm{mmHg}$, blood temperature $\approx 20^{\circ} \mathrm{C}$ ). The distal anastomosis in the proximal or middle aortic arch was performed. After heart de-airing and gradual rewarming, the patients were weaned from CPB.

\section{Degree of Postoperative Neurological Complications}

Major postoperative neurological dysfunctions were evaluated by a neurologist and serial brain CT. In addition, neurological dysfunctions were divided in the four sub-groups: 1) no neurological dysfunction; 2) temporary neurological dysfunctions (TND): TIA, delirium and disorientation ( $<24$ hours after extubation); 3) permanent neurological dysfunctions (PND): hemiplegia or paraplegia (>48 hours) that persisted after discharge at home; and 4) heavy neurological deficits (diffuse and irreversible brain damage or coma). Patients discharged were followed-up in regular intervals in outpatients' clinic with echocardiography and, if required, chest and brain CT scan.

\section{Statistical Analysis}

Continuous variables are presented as means \pm SD and categorical variables are expressed as percentages. Not normally distributed continuous variables are presented as medians (interquartile range). Univariate binary logistic regression analysis was performed to identify factors associated with postoperative mortality and/or neurological complications within 30 days from surgery. For 30-day mortality, the hospital length of stay and the presence of postoperative neurological complications were not evaluated as potential predictors to avoid selection bias (all subjects who died experienced postoperative neurological complications and presented less time of hospitalization). For postoperative neurological complications, where adequate number of events was yielded $(n=9)$, significant univariate predictors were further incorporated into the final multivariable logistic regression model. To address the small sample size of our study, we implemented exact logistic regression and resampling techniques. Exact logistic regression produces more accurate inference in small samples because it does not depend on asymptotic results and conditional maximum probability estimates were sequentially calculated for each predictor in multivariable logistic models by temporarily conditioning out the other independent variables. Bootstrapping with 1000 replications was conducted to replicate bias-corrected confidence intervals of the significant determinants of the outcomes on interest in univariate and multivariable regression models. However, due to the limited number of observations, the reported effect sizes for certain variables are still characterized by wide confidence intervals.

Statistical analysis was conducted using STATA package, version 11.1 (StataCorp, College Station, Texas, USA). We deemed statistical significance at $P<0.05$.

\section{RESULTS}

The cohort consisted of 34 male and 11 female patients. Mean age was $58 \pm 11.4$ years. In 7 patients, haemodynamic instability and in 2 patients minor neurological deficits were noted preoperatively. Preoperative data and baseline demographic characteristics are shown in Table 1.

CPB was instituted with: right or left carotid (connecting through a synthetic $10-\mathrm{mm}$ graft)/bicaval cannulation in 42 patients and femoral artery/bicaval cannulation in 3 patients. Combined procedures were performed in 12 patients. Median 
Table 1. Baseline demographic and preoperative data.

\begin{tabular}{|c|c|}
\hline Preoperative data & $\begin{array}{c}\text { No. of patients } \\
\text { Total } n=45\end{array}$ \\
\hline \multicolumn{2}{|l|}{ Sex } \\
\hline Male & $34(75.6)$ \\
\hline Female & $11(24.4)$ \\
\hline Age (years) & $58 \pm 11.4$ \\
\hline Mean body surface area (m²) & $2 \pm 0.24$ \\
\hline Preoperative creatinine plasma (mg/dL), median (IQR) & $0.9(0.8-1.3)$ \\
\hline Preoperative hemodynamic instability & $7(15.6)$ \\
\hline Previous cardiac surgery operation & $2(4.4)$ \\
\hline Preoperative NT-proBNP (pg/mL), median (IQR) & $247(114-816)$ \\
\hline Preoperative D-dimer ( $\mu \mathrm{g} / \mathrm{L})$, median (IQR) & $6503(3418-8610)$ \\
\hline
\end{tabular}

Data are presented as mean \pm SD or median (IQR) for continuous variables and as number and percentage for categorical variables. $\mathrm{IQR}=$ interquartile range; NT-proBNP=N-terminal prohormone of brain natriuretic peptide; $\mathrm{SD}=$ standard deviation

Table 2. Perioperative data.

\begin{tabular}{l|c}
\hline \multicolumn{1}{c|}{ Perioperative data } & $\begin{array}{c}\text { No. of patients } \\
\text { Total } \mathbf{n = 4 5} \text { (\%) }\end{array}$ \\
\hline Combined operations & 12 (26.7) \\
\hline Types of operations & 29 (64.4) \\
\hline Interposition graft replacement & $5(11.1)$ \\
\hline Interposition graft replacement + modified Bentall operation & $3(6.7)$ \\
\hline Interposition graft replacement + aortic valve replacement & $2(4.4)$ \\
\hline Interposition graft replacement + coronary bypass grafting & $6(13.3)$ \\
\hline Interposition graft replacement + aortic arch replacement & $41.5(30-54)$ \\
\hline Total circulatory arrest time (min), median (IQR) & $107(92-130)$ \\
\hline Aortic cross-clamp time (min), median (IQR) & $211(184-240)$ \\
\hline Cardiopulmonary bypass time (min), median (IQR) & $22.3(20.8-24)$ \\
\hline Bladder temperature during circulatory arrest ( $\left.{ }^{\circ} \mathrm{C}\right)$, median (IQR) & $7.33(7.29-7.35)$ \\
\hline pH during circulatory arrest, median (IQR) & \\
\hline
\end{tabular}

Data are presented as mean \pm SD or median (IQR) for continuous variables and as number and percentage for categorical variables. $\mathrm{IQR}=$ interquartile range; $\mathrm{SD}=$ standard deviation

circulatory arrest time was 41.5 (30-54) min and median minimum bladder temperature during circulatory arrest was 22.3 (20.8-24) ${ }^{\circ} \mathrm{C}$. Other perioperative details are presented in Table 2.

Major and minor postoperative complications and follow-up data such as postoperative atrial fibrillation (AF), postoperative open sternum, intensive care unit (ICU) stay, all postoperative neurological complications, 30-day mortality and other complications are listed in Table 3. During median follow-up of 6 (2-12) months the survival was $86.7 \%$ (39/45).

Unadjusted analysis of factors associated with 30-day mortality showed: preoperative hemodynamic instability (OR:
14.8, 95\% Cl: 2.41,90.6, $P=0.004)$ and postoperative open sternum (OR: 5.0, 95\% Cl: 1.041, 24.0, $P=0.044$ ) (Table 4).

Furthermore, unadjusted analysis revealed that severe neurological dysfunction correlated with: preoperative hemodynamic instability (OR: 8.8, 95\% Cl: 1.41, 54.9, $P=0.02)$ and postoperative sepsis or multiple organ dysfunction (OR: 13.6, 95\% $\mathrm{Cl}: 2.1,89.9, P=0.007)$ while bladder temperature during circulatory arrest $\left({ }^{\circ} \mathrm{C}\right)(\mathrm{OR}: 1.33,95 \% \mathrm{Cl}: 0.980,1.860, P=0.058)$ was marginally associated with this outcome (Table 5). Finally, by multivariate logistic regression analysis, postoperative sepsis/multiple organ dysfunction was associated (OR: 15.9, 95\% Cl: 1.05, 96.4, 
Table 3. Postoperative complications and follow-up data.

\begin{tabular}{|c|c|}
\hline Postoperative complications and follow-up data & $\begin{array}{l}\text { No. of Patients } \\
\text { Total } n=45(\%)\end{array}$ \\
\hline Atrial fibrillation & $11(24.4)$ \\
\hline Permanent pacemaker & $2(4.4)$ \\
\hline Pericardial effusion & $5(11.1)$ \\
\hline Mechanical ventilation $>48$ hours in intensive care unit & $29(64.4)$ \\
\hline Postoperative open sternum & $14(31.1)$ \\
\hline Postoperative acute kidney injury (increase postoperative $>50 \%$ of preoperative creatinine plasma) & $23(51.1)$ \\
\hline \multicolumn{2}{|l|}{ Postoperative neurological dysfunction: } \\
\hline No neurological dysfunction & $36(80)$ \\
\hline Temporary neurological dysfunction & - \\
\hline Permanent neurological dysfunction & $6(13.3)$ \\
\hline Heavy neurological dysfunction & $3(6.7)$ \\
\hline Postoperative transfusion of red blood cells (unit), median (range) & $10(2-38)$ \\
\hline Postoperative transfusion of fresh frozen plasma (unit), median (range) & $8(3-36)$ \\
\hline Postoperative creatinine plasma (mg/dL), median (IQR) & $1.6(1.3-2.3)$ \\
\hline Postoperative stay in ICU (days), median (IQR) & $8(3-9)$ \\
\hline Postoperative in-hospital stay (days), median (IQR) & $12(8-18)$ \\
\hline Follow-up (months), median (IQR) & $6(2-12)$ \\
\hline Overall mortality & $6(13.3)$ \\
\hline 30-days mortality & $3(6.7)$ \\
\hline All cause deaths during median follow-up 6 (2-12) months & $3(6.7)$ \\
\hline
\end{tabular}

Data are presented as mean \pm SD or median (IQR) for continuous variables and as number and percentage for categorical variables. Permanent neurological dysfunction (PND)=hemiplegia or paraplegia $>48$ hours after discharge at home. Heavy neurological deficits=diffuse and irreversible brain damage or coma.

ICU=intensive care unit; IQR=interquartile range

$P=0.045)$ with the incidence of severe postoperative neurological complications (Table 6) independently of other significant univariate predictors (i.e. bladder temperature during circulatory arrest and presence of preoperative hemodynamic instability).

\section{DISCUSSION}

Publications of series on operations in the ascending aorta and hemiarch continue to discuss advantages and disadvantages amongst different techniques particularly in $A A D$ pathology ${ }^{[1-7]}$ However, there is unanimity in that the most significant concern during this type of operations is the protection of the central nervous system (CNS) during the interval of hypothermic CA. The main issues that need to be addressed in these complex procedures are route of CPB establishment (site of arterial cannulation), core temperature management during operation and type of cerebral perfusion during CA with or without aortic arch repair.

\section{Arterial Cannulation Sites}

The optimal arterial cannulation site during proximal aortic arch surgery has been widely discussed over the years. Direct cannulation of the ascending aorta in patients who have an aortic aneurysm is an accepted technique and supported by many authors ${ }^{[8]}$. On the other hand, in cases with acute and chronic aortic dissection, the approach of arterial cannulation is controversial. Many techniques have been suggested in these cases: ascending aortic cannulation, right axillary or subclavian artery, right or left carotid artery, right or left common femoral artery and even transapical aortic cannulation ${ }^{[9-14]}$. These studies have demonstrated a relatively similar 30-day mortality regardless of the cannulation technique, while the incidence of stroke varied widely between 3.8 and 21\%. In 2010, Tiwari et al. ${ }^{[15]}$, after analysis of several studies, concluded that ascending aortic cannulation has promising results with a lower mortality rate, 
Table 4. Univariate risk factors for 30-day mortality.

\begin{tabular}{|c|c|c|c|c|c|}
\hline Variable & $\begin{array}{c}\text { No. of } \\
\text { patients }\end{array}$ & $\begin{array}{c}\text { 30-day } \\
\text { mortality }\end{array}$ & OR & $95 \% \mathrm{Cl}$ & $P$-value \\
\hline Overall & 45 & $3(6.7)$ & & & \\
\hline \multicolumn{6}{|l|}{ Preoperative factors } \\
\hline Age (years) & $58 \pm 11.4$ & & 0.909 & $(0.805-1.01)$ & $0.071^{*}$ \\
\hline Sex (female) & $11(26.19)$ & - & 0.775 & $(0-7.7)$ & 0.565 \\
\hline Preoperative hemodynamic instability & $7(15.6)$ & $2(4.4)$ & 14.8 & $(2.41-90.6)$ & $0.004^{*}$ \\
\hline Preoperative D-dimer & & & 1.001 & $(0.999-1.001)$ & 0.798 \\
\hline Preoperative NT-proBNP & & & 1.002 & $(0.999-1.001)$ & 0.658 \\
\hline \multicolumn{6}{|l|}{ Perioperative factors } \\
\hline Arterial cannulation site (femoral artery) & $3(6.7)$ & - & 3.74 & $(0-44.3)$ & 0.999 \\
\hline Total aortic arch replacement & $7(15.6)$ & - & 1.39 & $(0.14-15.9)$ & 0.999 \\
\hline Combined operation & $12(26.7)$ & - & 0.687 & $(0-6.8)$ & 0.554 \\
\hline Cardiopulmonary bypass time & & & 0.991 & $(0.955-1.019)$ & 0.581 \\
\hline Aortic cross-clamp time & & & 0.986 & $(0.933-1.028)$ & 0.584 \\
\hline Total circulatory arrest time & & & 0.957 & $(0.853-1.029)$ & 0.374 \\
\hline Bladder temperature during circulatory arrest & & & 1.29 & $(0.829-2.01)$ & 0.227 \\
\hline \multicolumn{6}{|l|}{ Postoperative factors } \\
\hline Postoperative open sternum & $14(31.1)$ & $2(4.4)$ & 5 & $(1.041-24.0)$ & $0.044^{*}$ \\
\hline Postoperative pericardial effusion & $5(11.1)$ & - & 2.07 & $(0-22)$ & 0.999 \\
\hline Postoperative atrial fibrillation & $11(24.4)$ & - & 0.775 & $(0-7.7)$ & 0.565 \\
\hline Postoperative stay in ICU & & & 0.581 & $(0.299-1.127)$ & 0.108 \\
\hline
\end{tabular}

$P$-values are derived from exact univariate logistic regression.

* Confidence intervals are derived from bootstrapping with 1000 replications.

$\mathrm{NT}$-proBNP=N-terminal prohormone of brain natriuretic peptide; ICU=intensive care unit

but a higher stroke rate in type A aortic dissections. In our study, the incidence of PND and 30-day mortality was $13.3 \%$ and $6.7 \%$, respectively. Although the numbers of patients in our study are too small to draw safe conclusions, the survival rate seems to be very good, with good survival in the medium term. Neurological complications, however, according to the above remain an issue.

\section{Temperature Management during Hypothermic Circulatory Arrest}

The goals of hypothermia during thoracic aortic surgery are reduction of brain metabolism and attenuation of CNS damage during CA. In 1975, Griepp et al. ${ }^{[16]}$ described four patients with successful outcome who underwent aortic arch replacement with prosthetic graft under deep hypothermic circulatory arrest (DHCA) with lowest esophageal temperature at $14^{\circ} \mathrm{C}$ and lowest rectal temperature at $18^{\circ} \mathrm{C}$. Decreased mortality and neurological complications were achieved with cerebral perfusion during CA. Deep hypothermic circulatory arrest with retrograde cerebral perfusion (DHCA/RCP) $\left(18^{\circ} \mathrm{C}\right)$ allowed longer CA times and improved brain protection ${ }^{[17]}$. In 1991, Bachet et al. ${ }^{[18]}$ published the technique with MHCA/ACP during transverse aortic arch repair (core temperature $25-28^{\circ} \mathrm{C}$ and brain perfused with blood cooled at $6-12^{\circ} \mathrm{C}$ ). This method created a favorable circumstance to perform more complex operations in the aortic arch, with simultaneous improvement of neurological and overall outcomes.

In 2011, the analysis of 1558 patients (GERAADA study) by Krüger et al. ${ }^{[19]}$ noted that relative increase in mortality was observed in patients with hypothermic $C A\left(<15^{\circ} \mathrm{C}\right)$ alone, even more so when CA arrest time exceeded $30 \mathrm{~min}$. Estrera et al. [20] used hypothermic CA (nasopharyngeal temperature $15-20^{\circ} \mathrm{C}$ ) with or without retrograde cerebral perfusion (RCP) and stroke rate and 30 -day mortality were $2.3 \%$ and $10.4 \%$, respectively. On the other hand, Urbanski et al..[21] analyzed 347 patients who underwent nonemergent arch surgery under MHCA with rectal temperature (28$34^{\circ} \mathrm{C}$ ) utilizing ACP. Their 30-day mortality and overall postoperative neurological dysfunction were $0.9 \%$ and $3.2 \%$, respectively. Perreas et al. ${ }^{[22]}$, in a retrospective analysis of 208 patients operated on with DHCA/RCP (temperature range $11-24^{\circ} \mathrm{C}$ ), concluded that the core temperature within the specific range was not a risk factor for 30day mortality and severe neurological events. In another recent study, Zierer et al. ${ }^{[4]}$ noted that increase of the core temperature 
Table 5. Univariate risk factors for postoperative severe neurological complication.

\begin{tabular}{|c|c|c|c|c|c|}
\hline Variable & $\begin{array}{c}\text { No. of } \\
\text { patients }\end{array}$ & $\begin{array}{l}\text { Postoperative } \\
\text { neurological } \\
\text { complication }\end{array}$ & OR & $95 \% \mathrm{Cl}$ & $P$-value \\
\hline Overall & $45(100.0)$ & & & & \\
\hline \multicolumn{6}{|l|}{ Preoperative factors } \\
\hline Age (years) & $58 \pm 11.4$ & & 0.977 & $(0.915-1.042)$ & 0.489 \\
\hline Sex (female) & $11(26.19)$ & $1(2.2)$ & 0.338 & $(0.007-3.1)$ & 0.416 \\
\hline Reoperation & $2(4.4)$ & - & 1.64 & $(0-22)$ & 0.999 \\
\hline Preoperative hemodynamic instability & $7(15.6)$ & $4(8.9)$ & 8.8 & $(1.41-54.9)$ & $0.02^{*}$ \\
\hline Preoperative NT-proBNP & & & 0.999 & $(0.999-1.001)$ & 0.621 \\
\hline \multicolumn{6}{|l|}{ Perioperative factors } \\
\hline Arterial cannulation site (common carotid artery with graft) & $42(93.3)$ & $8(17.8)$ & 0.480 & $(0.022-31)$ & 0.999 \\
\hline Arterial cannulation site (femoral artery) & $3(6.7)$ & $1(2.2)$ & 2.13 & $(0.426-10.6)$ & 0.358 \\
\hline Total aortic arch replacement & $7(15.6)$ & $2(4.4)$ & 1.75 & $(0.139-13.8)$ & 0.614 \\
\hline Combined operation & $12(26.7)$ & $2(4.4)$ & 0.748 & $(0.065-4.93)$ & 0.999 \\
\hline Cardiopulmonary bypass time & & & 1.002 & $(0.985-1.018)$ & 0.805 \\
\hline Aortic cross-clamp time & & & 1.01 & $(0.981-1.029)$ & 0.673 \\
\hline Total circulatory arrest time & & & 1.01 & $(0.974-1.037)$ & 0.686 \\
\hline Bladder temperature during circulatory arrest & & & 1.33 & $(0.980-1.86)$ & $0.058^{*}$ \\
\hline \multicolumn{6}{|l|}{ Postoperative factors } \\
\hline Postoperative open sternum & $14(31.1)$ & $3(6.7)$ & 1.13 & $(0.155-6.6)$ & 0.999 \\
\hline Postoperative acute kidney injury & $23(51.1)$ & $6(13.3)$ & 2.2 & $(0.394-15.7)$ & 0.459 \\
\hline Postoperative pericardial effusion & $5(11.1)$ & $1(2.2)$ & 1 & $(0.018-12.2)$ & 0.999 \\
\hline Postoperative permanent pacemaker implantation & $2(4.4)$ & - & 1.64 & $(0-22)$ & 0.999 \\
\hline Postoperative atrial fibrillation & $11(24.4)$ & $3(6.7)$ & 1.73 & $(0.228-10.6)$ & 0.666 \\
\hline Postoperative sepsis or multiple organ dysfunctions & $6(13.3)$ & $4(8.9)$ & 13.6 & $(2.1-89.9)$ & $0.007^{*}$ \\
\hline Postoperative stay in ICU & & & 1.040 & $(0.966-1.12)$ & 0.254 \\
\hline Postoperative hospital stay & & & 1.031 & $(0.982-1.1)$ & 0.180 \\
\hline
\end{tabular}

$P$-values are derived from exact univariate logistic regression.

* Confidence intervals are derived from bootstrapping with 1000 replications.

$\mathrm{NT}$-proBNP=N-terminal prohormone of brain natriuretic peptide; ICU=intensive care unit

Table 6. Multivariable logistic regression analysis for the main determinants of the incidence of postoperative severe neurological outcome $(n=45)$.

\begin{tabular}{|c|c|c|c|}
\hline Variable & OR & $95 \% \mathrm{Cl}$ & $P$-value \\
\hline Bladder temperature during circulatory arrest & 1.28 & $0.885-1.89$ & 0.183 \\
\hline Preoperative hemodynamic instability & 5.5 & $0.454-77$ & 0.221 \\
\hline Postoperative sepsis or multiple organ dysfunction & 15.9 & $1.05-96.4$ & $0.045^{*}$ \\
\hline
\end{tabular}

$P$-values are derived from exact logistic regression. 
$\left(28-30^{\circ} \mathrm{C}\right)$ during $\mathrm{CA}$ with implementation ACP allowed more time (CA>90 min), more complex corrections of ascending aorta and aortic arch pathology with low incidence of postoperative complications (new postoperative neurological deficits were 7\%). Leshnower et al. ${ }^{[23]}$ analyzed 500 patients who underwent a hemiarch replacement under mild $\left(28.6^{\circ} \mathrm{C}\right)$ vs. moderate $\left(24.3^{\circ} \mathrm{C}\right)$ hypothermic CA with unilateral ACP with operative mortality of $4.2 \%$ vs. $4.8 \%(P=0.80)$ and no differences in TND between the two groups. However, the incidence of PND was reduced in mild vs. moderate hypothermia ( $2.5 \%$ vs.7.2\%) $(P=0.01)$.

\section{Type of the cerebral protection and perfusion: DHCA alone, DHCA/RCP, deep hypothermic CA with unilateral or bilateral cerebral perfusion (DHCA/UACP or BACP), or moderate hypothermic $C A$ with unilateral or bilateral cerebral perfusion (MHCA/UACP or BACP)?}

In hemiarch with or without total aortic arch replacement, with or without stent grafting, the question remains: which method of brain protection is most effective and safe during these complex operations, particularly in patients with AAD?

Usui et al. ${ }^{[1]}$ analyzed 2792 patients and found no differences between the ACP and RCP groups in 30-day mortality $(3.4 \%$ vs. $2.4 \%$ ) and stroke rate ( $5 \%$ vs. $3 \%$ ), but in the subgroup with RCP higher incidence of transient neurological dysfunction (5.8\%) was observed. Misfeld et al. ${ }^{[2]}$ divided 636 patients who underwent aortic arch surgery in four groups: UACP, bilateral ACP (BACP), DHCA/RCP and DHCA only. The study showed that early mortality and five-year survival were not different between the surgical groups, but stroke rate was different in patients who did not receive ACP $(P=0.035)$. Urbanski et al. ${ }^{[21]}$ presented results of non-emergent aortic arch surgery using mild to moderate hypothermic CA $\left(31.5 \pm 1.6^{\circ} \mathrm{C}\right)$ with ACP (blood temperature $28^{\circ} \mathrm{C}$ ) in 347 patients. The results show that 30-day mortality was $0.9 \%$, and PND and TND observed in $0.9 \%$ and $2.3 \%$, respectively. On the other hand, Estrera et al.[20] reported the study with 1107 patients who operated under DHCA/RCP in $82 \%$ of cases, and the results were 30 -day mortality and stroke rate occurred $10.4 \%$ and $2.8 \%$, respectively. After comparative analysis of 1558 patients with AAD, Krüger et al. ${ }^{[19]}$ concluded that 30-day mortality was higher in the DHCA group (19.4\%) than in the BACP (15.9\%) and UACP (13.9\%) groups ( $P<0.05)$. The same study noted that PND were: DHCA-14.9\%, BACP-14.1\% and UACP-12.6\%. The most recent results from the Japanese AAD database (2016) repair with ACP vs. RCP did not show significant differences regarding mortality and postoperative neurological dysfunctions rates $\left(11.2 \%\right.$ vs. 9.7\% ${ }^{[3]}$. Nowadays, many studies discuss the incidence of stroke and mortality rate after AAD repair with hemiarch versus hemiarch plus total arch replacement (with or without antegrade stent grafting ${ }^{[3,24-26]}$. After analysis, the results show that the rates of mortality and stroke are similar between the two groups. However, it is possibly relevant regarding false lumen thrombosis rate and reduction of late reoperation rate in aortic arch and descending aorta. In 2015, Di Bartolomeo et al. ${ }^{[26]}$, in a review of AAD type A repair with frozen elephant trunk technique, noted that mortality and postoperative stroke range were $0-27.7 \%$ and $0-12 \%$, respectively. In addition, in the same study, the authors revealed that the spinal cord injury rate ranged from 0 to $13.8 \%$. It is evident that postoperative neurological complications range in the literature from 0 to $39.7 \%$.

\section{CONCLUSION}

In aortic arch surgery for $A A D$, the total CA can be avoided by maintaining cerebral perfusion. Thus, continuous cerebral perfusion via UACP or BACP resulted in a reduction of postoperative mortality. However, the postoperative severe neurological complications remain at high frequency, requiring further refinement of this technique. Reduction of these major postoperative complications should be explored in multicenter studies.

\section{Limitations}

This is clearly a retrospective analysis with a small cohort, albeit with consecutive patients from a single unit. Two patients with preoperative TIA were included in our study with possible impact on severe postoperative neurological complications. Furthermore, most patients with AAD were operated emergently without accurate preoperative neurological assessment and without preoperative brain CT. On the other hand, more extensive follow-up is required to demonstrate potential improvements in the long-term outcomes.

\section{Authors' roles \& responsibilities}

GS Took part in the care of the patients and contributed equally in data collection and manuscript preparation; final approval of the version to be published

CK Took part in the care of the patients and contributed equally in data collection and manuscript preparation; final approval of the version to be published

CC Took part in the care of the patients and contributed equally in data collection and manuscript preparation; final approval of the version to be published

GG

Contributed in the statistical analysis of the data; final approval of the version to be published

IK Took part in the care of the patients and contributed equally in data collection and manuscript preparation; final approval of the version to be published

TA Took part in the care of the patients and contributed equally in data collection and manuscript preparation; final approval of the version to be published

KP Supervision of this report; final approval of the version to be published

\section{REFERENCES}

1. Usui A, Miyata H, Ueda Y, Motomura N, Takamoto S. Risk-adjusted and case-matched comparative study between antegrade and retrograde cerebral perfusion during aortic arch surgery: based on the Japan Adult Cardiovascular Surgery Database: the Japan Cardiovascular Surgery Database Organization. Gen Thorac Cardiovasc Surg. 2012;60(3):132-9. 
2. Misfeld M, Leontyev S, Borger MA, Gindensperger O, Lehmann S, Legare JF, et al. What is the best strategy for brain protection in patients undergoing aortic arch surgery? A single center experience of 636 patients. Ann Thorac Surg. 2012;93(5):1502-8.

3. Okita Y. Current surgical results of acute type A aortic dissection in Japan. Ann Cardiothorac Surg. 2015;5(4):368-76.

4. Zierer A, El-Sayed Ahmad A, Papadopoulos N, Moritz A, Diegeler A, Urbanski PP. Selective antegrade cerebral perfusion and mild $\left(28^{\circ} \mathrm{C}-30^{\circ} \mathrm{C}\right)$ systemic hypothermic circulatory arrest for aortic arch replacement: results from 1002 patients. JThorac Cardiovasc Surg. 2012;144(5):1042-9.

5. Sugiura T, Imoto K, Uchida K, Minami T, Yasuda S. Comparative study of brain protection in ascending aorta replacement for acute type A aortic dissection: retrograde cerebral perfusion versus selective antegrade cerebral perfusion. Gen Thorac Cardiovasc Surg. 2012;60(10):645-8.

6. Han QQ, Song ZG, Zou LJ, Han L, Lu FL, Lang XL, et al. Reinforced aortic root reconstruction for acute type A aortic dissection involving the aortic root. Rev Bras Cir Cardiovasc. 2013;28(2):190-9.

7. Pinheiro BB, Fagundes WV, Muniz LF, Dreifaldt M, Arbeus M, Souza DS. Dacron graft intussusception technique for treatment of type A aortic dissections: technical notes and preliminary results. Braz J Cardiovasc Surg. 2016;31(2):115-9

8. Khaladj N, Shrestha M, Peterss S, Strueber M, Karck M, Pichlmaier M, et al. Ascending aortic cannulation in acute aortic dissection type A: the Hannover experience. Eur J Cardiothorac Surg. 2008;34(4):792-6.

9. Fusco DS, Shaw RK, Tranquilli M, Kopf GS, Elefteriades JA. Femoral cannulation is safe for type A dissection repair. Ann Thorac Surg. 2004;78(4):1285-9.

10. Strauch JT, Spielvogel D, Lauten A, Lansman SL, McMurtry K, Bodian CA, et al. Axillary artery cannulation: routine use in ascending aorta and aortic arch replacement. Ann Thorac Surg. 2004;78(1):103-8.

11. Wada S, Yamamoto S, Honda J, Hiramoto A, Wada H, Hosoda Y. Transapical aortic cannulation for cardiopulmonary bypass in type A aortic dissection operations. J Thorac Cardiovasc Surg. 2006;132(2):369-72.

12. Urbanski PP, Lenos A, Lindemann Y, Weigang E, Zacher M, Diegeler A. Carotid artery cannulation in aortic surgery. J Thorac Cardiovasc Surg. 2006;132(6):1398-403.

13. Kamiya H, Kallenbach K, Halmer D, Ozsöz M, Ilg K, Lichtenberg A, et al. Comparison of ascending aorta versus femoral artery cannulation for acute aortic dissection type A. Circulation. 2009;120(11 Suppl):S282-6.

14. Sosnowski AW, Jutley RS, Masala N, Alexiou C, Swanevelder J. How I do it: transapical cannulation for acute type-A aortic dissection. J Cardiothorac Surg. 2008;3:4.

15. Tiwari KK, Murzi M, Bevilacqua S, Glauber M. Which cannulation (ascending aortic cannulation or peripheral arterial cannulation) is better for acute type A aortic dissection surgery? Interact Cardiovasc Thorac Surg. 2010;10(5):797-802.

16. Griepp RB, Stinson EB, Hollingsworth JF, Buehler D. Prosthetic replacement of the aortic arch. J Thorac Cardiovasc Surg. 1975;70(6):1051-63.

17. Ueda Y, Miki S, Kusuhara K, Okita Y, Tahata T, Yamanaka K. Deep hypothermic systemic circulatory arrest and continuous retrograde cerebral perfusion for surgery of aortic arch aneurysm. Eur J Cardiothorac Surg. 1992;6(1):36-41.

18. Bachet J, Guilmet D, Goudot B, Termignon JL, Teodori G, Dreyfus G, et al. Cold cerebroplegia. A new technique of cerebral protection during operations on the transverse aortic arch. J Thorac Cardiovasc Surg. 1991;102(1):85-93.

19. Krüger T, Weigang E, Hoffmann I, Blettner M, Aebert H; GERAADA Investigators. Cerebral protection during surgery for acute aortic dissection type A: results of the German Registry for Acute Aortic Dissection Type A (GERAADA). Circulation. 2011;124(4):434-43.

20. Estrera AL, Miller CC 3rd, Lee TY, Shah P, Safi HJ. Ascending and transverse aortic arch repair: the impact of retrograde cerebral perfusion. Circulation. 2008;118(14 Suppl):S160-6.

21. Urbanski PP, Lenos A, Bougioukakis P, Neophytou I, Zacher M, Diegeler A. Mild-to-moderate hypothermia in aortic arch surgery using circulatory arrest: a change of paradigm? Eur J Cardiothorac Surg. 2012;41 (1):185-91.

22. Perreas K, Samanidis G, Dimitriou S, Kalogris P, Balanika M, Antzaka C, et al. Outcomes after ascending aorta and proximal aortic arch repair using deep hypothermic circulatory arrest with retrograde cerebral perfusion: analysis of 207 patients. Interact Cardiovasc Thorac Surg. 2012;15(3):456-61.

23. Leshnower BG, Myung RJ, Thourani VH, Halkos ME, Kilgo PD, Puskas JD, et al. Hemiarch replacement at $28^{\circ} \mathrm{C}:$ an analysis of mild and moderate hypothermia in 500 patients. Ann Thorac Surg. 2012;93(6):1910-5.

24. Vallabhajosyula P, Gottret JP, Robb JD, Szeto WY, Desai ND, Pochettino A, et al. Hemiarch replacement with concomitant antegrade stent grafting of the descending thoracic aorta versus total arch replacement for treatment of acute DeBakey I aortic dissection with arch tear. Eur J Cardiothorac Surg. 2016:49(4):1256-61.

25. Omura A, Miyahara S, Yamanaka K, Sakamoto T, Matsumori M, Okada $\mathrm{K}$, et al. Early and late outcomes of repaired acute DeBakey type I aortic dissection after graft replacement. J Thorac Cardiovasc Surg. 2016;151(2):341-8.

26. Di Bartolomeo R, Pantaleo A, Berretta P, Murana G, Castrovinci S, Cefarelli $M$, et al. Frozen elephant trunk surgery in acute aortic dissection. J Thorac Cardiovasc Surg. 2015;149(2 Suppl):S105-9. 